\title{
Numerical and experimental study of the dynamics of axisymmetric slender liquid bridges
}

\author{
By JOSE MESEGUER AND ANGEL SANZ \\ Laboratorio de Aerodinámica. E.T.S.I. Aeronáuticos, Universidad Politécnica, \\ 28040 Madrid, Spain
}

(Received 2 November 1983 and in revised form 12 October 1984)

A one-dimensional inviscid slice model has been used to study numerically the influence of axial microgravity on the breaking of liquid bridges having a volume close to that of gravitationless minimum volume stability limit. Equilibrium shapes and stability limits have been obtained as well as the dependence of the volume of the two drops formed after breaking on both the length and the volume of the liquid bridge. The breaking process has also been studied experimentally. Good agreement has been found between theory and experiment for neutrally buoyant systems.

\section{Introduction}

A number of recently published papers deal with the floating zone problem through idealized models in which, generally, phase changes are avoided. The most used model consists of a liquid bridge, either under gravitationless conditions or subject to a small axial gravity held by surface tension forces between two parallel disks with a common axis (figure 1). Besides the analytical and experimental approaches made on thermal problems (mainly on Marangoni convection). the liquid bridge problem has received attention from many investigators: the shapes and static stability of li(puid bridges at rest under gravitationless conditions have been studied by Haynes (1970). Erle. Gillette \& Dyson (1970). Gillette \& Dyson (1971), Martinez (1976). Da Riva \& Martinez (1979), Slobozhanin (1982), Martinez (1983), Meseguer (1984), among others. The influence of microgravity or disks rotation (or both) have been considered by Coriell \& Cordes (1977). Coriell. Hardy \& Cordes (1977), Martinez (1978a.b). Boucher \& Evans (1980), Brown \& Seriven (1980), Da Riva (1981). Ungar \& Brown (1982). and Vega \& Perales (1983) among others. In addition, attempts have been made to solve some aspects of the dynamies of liquid bridges: the spin-up from rest has been considered in Da Riva \& Meseguer (1978) and Da Riva \& Manzano (1981). while the steady problem of a liquid bridge with disks rotating at different relocities was examined by Harriot \& Brown (1983), and the breaking problem has been treated by Meseguer (1983a.b). Meseguer. Sanz \& Riras (1983) and Riras \& Meseguer (1984).

In this paper the intuence of axial microgravity on the minimum volume stability limit of non-eylindrical liquid bridges is studied numerically from a dynamic point of view. The method is used to calculate the static characteristies of the liquid bridge. such as the equilibrium shapes and the minimum volume stability limit. and overall dynamic characterist ics of the breaking process, i.e. the influence of axial microgravity. the length of the liquid bridge. and the volume of the liquid column on the volume of the two caps resulting after liquid bridge breaking. Characteristics of the breaking process are required to evaluate the ability of the slice model to predict the behaviour of axisymmetric stender liquid bridges. Numerical results shown in Meseguer 


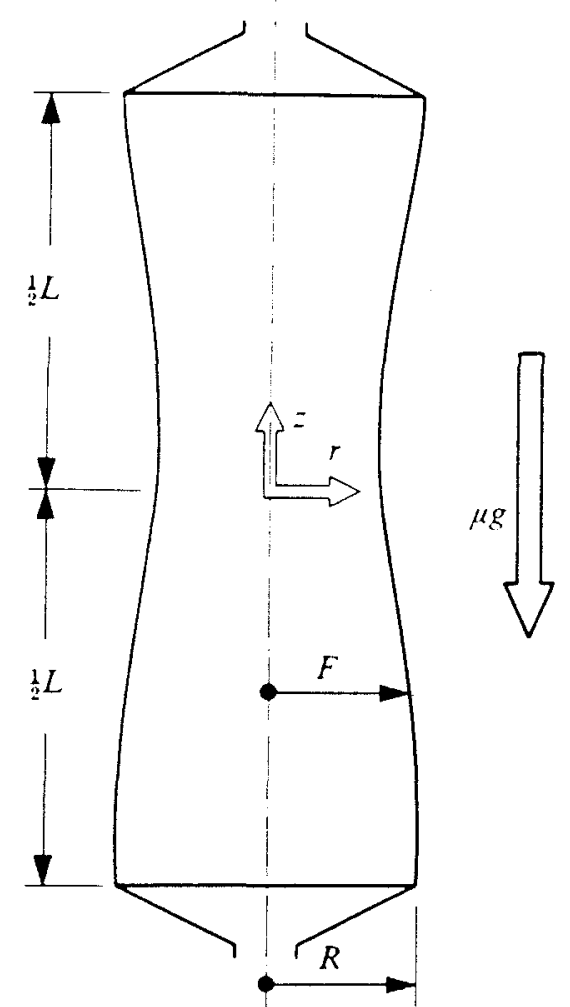

FIG RE: 1. Geometry and coordinate system for the liquid bridge problem.

$(1983 a, b)$. Meseguer ef al. (1983) and in this paper suggest that the volume of the caps mainly depends on both the length and the whole volume of the liquid bridge and not on the initial perturbation of the interface (provided these perturbations are small enough). Cap volume measurements have been used to compare theory with experiments.

From the experimental point of view the studies of liquid bridges carried out in earth-based laboratories are strongly constricted because the maximum stable length of a liquid bridge is of the order of a few millimetres. Slender liquid bridges can only be obtained by working on a very small scale, or by simulating microgravity conditions by using the neutral buoyancy with one liquid surrounded by a second with which it is immiscible but of precisely the same density. Neutral buovancy has been used by Mason (1970), Carruthers \& Grasso (1972), Coriell et al. (1977), Rodot, Bisch \& Lasek (1979). Tagg et al. (1980), Bisch, Lasek \& Rodot (1982), Elagin Lebedev \& Tsmelev (1982), Sanz (1983), Sanz \& Martinez (1983), among others. This experimental technique is very appropriate for hydrostatic studies. In the case of dynamic processes the presence of the outer liquid could modify the liquid bridge behaviour. However, available numerical results concerning non-rotating liquid bridges (Sanz 1983) show that the influence of the outer liquid on the volume of the drops resulting after liquid column breaking may be very small.

\section{Mathematical model}

In the following, unless otherwise stated, all physical quantities are made dimensionless using the characteristic length $R$, the radius of the disks, and the characteristic time $\left(\rho R^{3} / \sigma\right)^{\frac{1}{2}}, \rho$ being the liquid density and $\sigma$ the surface tension.

To calculate the evolution of the liquid bridge a one-dimensional inviscid slice 
model (similar to the model used by Lee (1974) in capillary jet theory) has been used. This model can be deduced from the Euler equations by assuming the axial velocity $W$ to be dependent upon the axial coordinate $z$ and the time $t$ but not upon the radial coordinate $r$. This one-dimensional model has been used also by Pimbley (1976) and Pimbley \& Lee (1977) in the study of the breaking of capillary jets; by Cram (1983) in the study of the formation of droplets in welding processes, and by Meseguer (1983a.b). Meseguer et al. (1983), Sanz (1983) and Rivas \& Meseguer (1984) in the analysis of liquid bridge dynamics. Details of numerical integration of the differential equations set can be found in Meseguer (1983a). In the slice model the radial momentum equation becomes decoupled, and the following equations of motion result:

Continuity equation

$$
\frac{\partial S}{\partial t}+\frac{\partial Q}{c z}=0
$$

Axial momentum equation

$$
\frac{\partial Q}{\partial t}+\frac{\partial}{\partial z}\left(\frac{Q^{2}}{S}\right)=-S \frac{\partial P}{\partial z}
$$

where the reduced pressure $P$, which accounts for both capillary and hydrostatic pressures. is given by

$$
P=4\left[2 S+\left(\frac{\partial S}{\partial z}\right)^{2}-S \frac{C^{2} S}{\hat{C}^{2} z^{2}}\right]\left[4 S+\left(\frac{\partial S}{\partial z}\right)^{2}\right]^{-\frac{3}{2}}+B O \cdot z
$$

In these expressions $S=F^{\prime \prime}$ (where $r=F(z . l)$ stands for the equation of the interface shape) and $Q=W F^{2}$ are proportional to the ross-sectional area and the axial momentum of each slice, respectively. $B_{0}$ is the static Bond number $B_{0}=\rho g R^{2} / \sigma$ where $g$ is the aceeleration due to mierogravity. Boundary conditions are:

$$
S( \pm A . t)=1 . \quad Q( \pm A . t)=0
$$

where $A=L / 2 R$ is the slenderness. Initial conditions are:

$$
S(z, 0)=F_{0}^{\prime}(z) . \quad(Q(0, t)=0 .
$$

$F_{0}$ being the initial interfare shape. Which is related to the volume enclosed through

$$
V^{\prime}=\pi \int_{-1}^{1} F_{0}^{\prime \prime}(z) \mathrm{d} z
$$

\section{Equilibrium shapes}

Equilibrium shapes are caleulated in liquid bridge hydrostaties by solving (2..3) taking the redued pressure $P$ as constant along the liquid column. Equation (2.3) with $x( \pm .1)=1$ is a two-point boundary problem with the additional complisation that $P$ is unknown and must be chosen to vield the correct liquid bridge volume. Equation (2.3) is usually solved as an initial-value problem (Coriell et al. 1977: Hartinez 1978 a) hy guessing values of both $P$ and the edge contact angle at one of the disks. In general. the values of the slenderness. the edge contact angle at the opposite disk and the liquid bridge volume obtained from the initial guess will not be the desired ones. and some iteration procedure must be adopted. In this paper we have tried a dynamic mothod to caleulate liquid bridge equilibrium shapes in which boundary eonditions at the disks are automatieally met, and phrsical variables such as the slenderness and the volume are the problem input. 

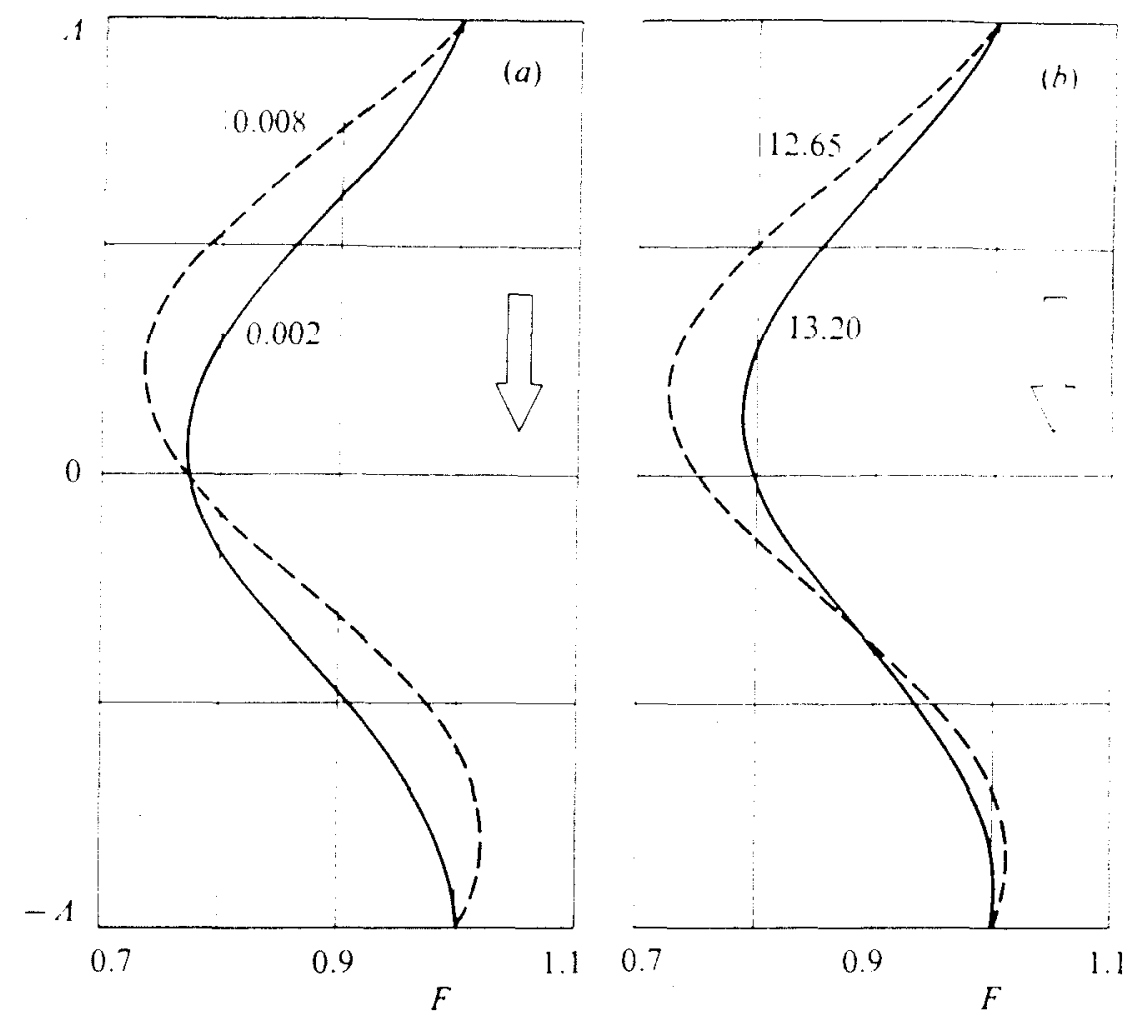

Fures: 2. Equilibrium interface shapes of liquid bridges with a slenderness $.1=2.6$. The interface shates in (a) correspond to liguid bridges with the sime solume $r=12.9$ subject to different Bond numbers, whereas those of $(b)$ correspond to liquid bridges having different rolumes subjected to the same Bond number $B(=0.005$. Numbers on the curves indicate the value of the Bond number in (a) and the volume in (l)).

The basic idea may be explained in a few words: the slice model allows us to calculate the oscillatory motion around some equilibrium shape, provided the initial configuration lies in the stable region. so if some appropriate dissipative effect is introduced into the model the oscillation will be damped. and the process will tend to the equilibrium shape. To define the initial configuration the following expression for the interface shape has been taken:

$$
S_{0}(z)=1+\left(\frac{V}{2 \pi \Lambda}-1\right)\left(1+\cos \frac{\pi z}{\Lambda}\right)+2 B o\left(z-\frac{A}{\sin A} \sin z\right)
$$

and. to estimate the accuracy in calculating the equilibrium interface shapes, a parameter giving the maximum pressure difference along the liquid bridge has been introduced

$$
\Delta P=\left(P_{\max }-P_{\min }\right) / P_{\max } .
$$

Let us assume that once the volume. the Bond number and the slenderness, and thence the interface shape as given by (3.1), are fixed, the evolution of the liquid bridge is calculated by using the slice model. The difference between capillary and hydrostatic (if it exists) pressure gradients generates a velocity field, and the liquid flows from the high- to the low-pressure regions. The interface shape changes. tending to smooth out the pressure distribution; since the liquid is assumed to be inviscid, when the configuration is close to equilibrium, the existing kinetic energy causes this position to be overpassed and the liquid bridge interface distorts in such a way that pressure gradients arise, tending to brake the movement. In consequence, if the initial configuration is stable, the liquid bridge will oscillate around some equilibrium interface shape. According to these considerations, the kinetic energy will be a 
maximum when $\Delta P$ is a minimum; therefore, if at that moment the relocity field is cancelled, the resulting configuration will have less energy than the initial one, $\Delta P$ being closer to zero than at the starting time. Taking this last interface shape as the initial one of a new run, a third interface shape even closer to the equilibrium one will result, and so on. Calculations hare been stopped when $\Delta P$ becomes smaller than a prefixed value which ranges from 0.005 at $A=2.0$ to 0.001 at $A=3.0$. Some of the calculated interface equilibrium shapes are shown in figure 2 .

\section{Stability limits and breaking process}

The evolution of axisymmetric liquid bridges subject to a small axial gravity has been numerically studied for three values of the Bond number. Bo $=0.01,0.005$ and 0.002 (calculations have been performed on a Hewlett-Packard 9836 desktop computer using HP-PASCAL language).

Stability limits have been calculated as follows. Assume a liquid bridge having slenderness $A$ and volume $V$ in equilibrium under a Bond number $B i$. Such a configuration, which is stable, is perturbed by increasing the Bond number from the initial value $B i$ to a new value $B o>B i$. If the perturbation $B o-B i$ is large enough the liquid bridge will break in two drops. The evolution of the liquid bridge interface is calculated by using the slice model. and the breaking time $t_{\mathrm{b}}$ (the time spent by the liquid bridge to reduce the neck radius from its initial value to zero) and the partial volume $v_{\mathrm{p}}$ (the larger drop volume to the whole liquid bridge volume ratio) are obtained. + The breaking time increases as the volume of the liquid bridge grows, as shown in figures 4 and 5 . and becomes infinite at the eritical value $V_{m}(A . B i . B o)$. For $V>V_{m}$ no breaking oceurs: the liquid bridge under gravity given by $B$ o is stable for the initial condition $B i$ and the perturbation imposed (represented by $B o-B i$ ) and. thence. $I_{\mathrm{m}}$ is just the minimum-volume stability limit for the assumed ralues of $A$. $B i$ and $B o$.

We discuss now the case $A=2.6$ for which a large number of initial conditions have been considered. The results to be analysed are shown in the lower plot of figure 4 (the results obtained for $A=3.0,2.3,2.15$ and 2.0 are plotted in figure 5). In figlire 4 . for each value of $B o, V_{\mathrm{m}}(A, B i, B o)$ decreases as $B i$ increases. The static minimum volume stability limit would be obtained by considering ralues of $B i$ as close as possible to the value of $B o$, formally when $B i=B o$. which is numerically unat tainable. To avoid this problem static stability limits have been calculated by extrapolation. In figure 6 the difference in volume $V_{m}(2.6 . B i . B o)-V_{m}(2.6 .0 . B o)$ at two stability limits only distinguished by their initial conditions has been represented for three values of $B o$. Two main aspects may be noted from figure 6 : first that $I_{m}(A . B i$. Bo ) varies almost linearly with $B i$ : and secondly that, for a given slenderness. the influence of initial conditions is the same no matter what the ralue of $B_{0}$ is. In consequence. for other values of the slenderness it will be enough to determine this initial-ronditions alibration curve here performed by alculating at least three points of the curve (for example $V_{\mathrm{m}}(A .0 .0 .01)$. $V_{\mathrm{m}}(A .0 .005 .0 .01)$ and $\left.V_{\mathrm{m}}(1.0 .0)(0.0 .01)\right)$. and one

+ In the breaking process calculations are -topped when the neck radius becomes smaller than 0.1 because of numerical instabilities (spatial and time derivatives of both st and (p become very large in the neck recion). At this point both the breaking time $t_{b}$ and the partial rolume pare well detined. In effect as shown in tigure 3 tor a typical liquid bridge contiguration. neek radius varies with time in such a way that when the stopping point is reached its slope is almost intinite. The slope of the curve griving the time variacion of the volume of liquid enelesed between one of the disks and the neck hridge vanishes under the same condition and the value of en is dearly detined also. 


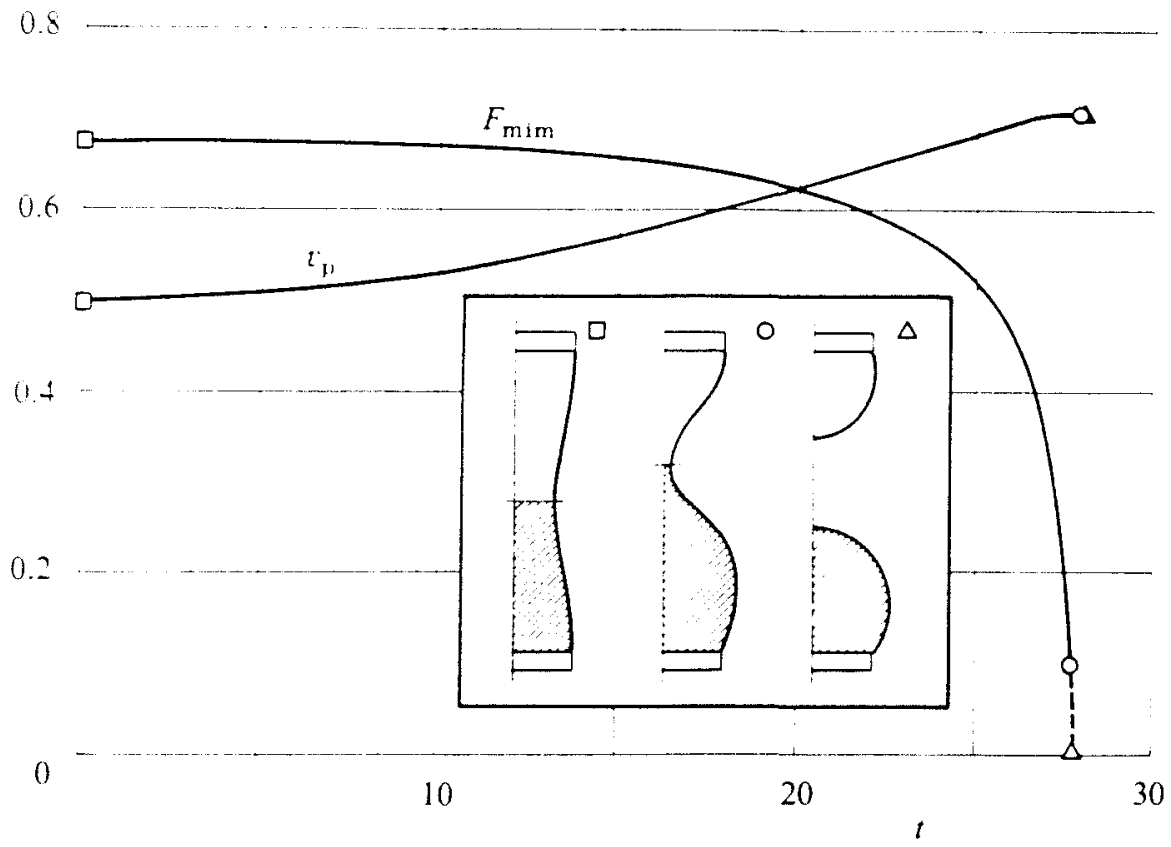

Futare 3 . Variation with time $t$ of neck radius $F_{\min }$ and partial volume $r_{n}$ of a typical liquid bridge

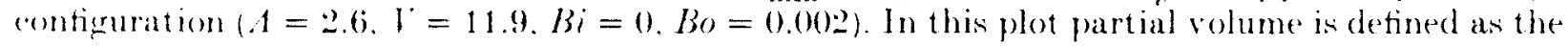
largere fraction of the liguid bridge volume enclosed between the neck and one of the disks. The symbols indicate the interface shape as stetched in the insert.

representative point for the other two values of $B$ o (i.e. $I_{m}(A .0 .0 .002)$ and $V_{\mathrm{m}}($ A. (). ().00i $\left.)\right)$.

The partial volume $c_{p}$ increases with liquid bridge volume $V$. but the rate of growth remains finite and even becomes smaller as $I$ increases, in such a way that for a liquid bridge at the static stability limit (whose volume is $V_{\mathrm{m}}(A, B o, B o)$ ) the partial volume is clearly defined. In table 1 the minimum rolume stability limits and the partial volume at stability limits. resulting from figures 4 and 5 , are summarized. In table 2 the static minimum rolume stability limits are presented, these ralues being obtained by the extrapolation method explained above.

The influence of Bond number on the static minimum volume stability limits and the dependence on Bond number of the partial volume at these limits have been represented in figures 7 and 8 , respectively. Liquid bridges become more sensitive to Bond number as $A$ increases. To be able to produce a bridge with Bond numbers $B o$ from 0 to 0.01 the liquid bridge volume needs to be increased by over $3 \%$ at $A=2.15$, whereas the increase must be of $16 \%$ at $A=3.0$. Concerning $v_{p}$, the results are in accordance with those expected from experimental evidence. The volume of the larger drop resulting after breaking increases with the Bond number.

Additional conclusions concerning partial volume can be deduced from figures 4 and 5 . These results corroborate the previous ones (Meseguer 1983a,b; Meseguer et al. 1983): $r_{p}$ seems to be an intrinsic feature of liquid bridge breaking, depending mainly on both the slenderness of the bridge and on the rolume of liquid enclosed. but not on the initial condition and breaking perturbation ( $B i$ and $B o-B i$. respectively). This dependence is represented in figure 9 , as the partial volume as a function of the liquid bridge volume for several values of $A$, which has been plotted from data presented in figures 7 and 8 (in figure 9 , due to scale constraints, $V_{\mathrm{m}} / \mathrm{e}^{A}$ 


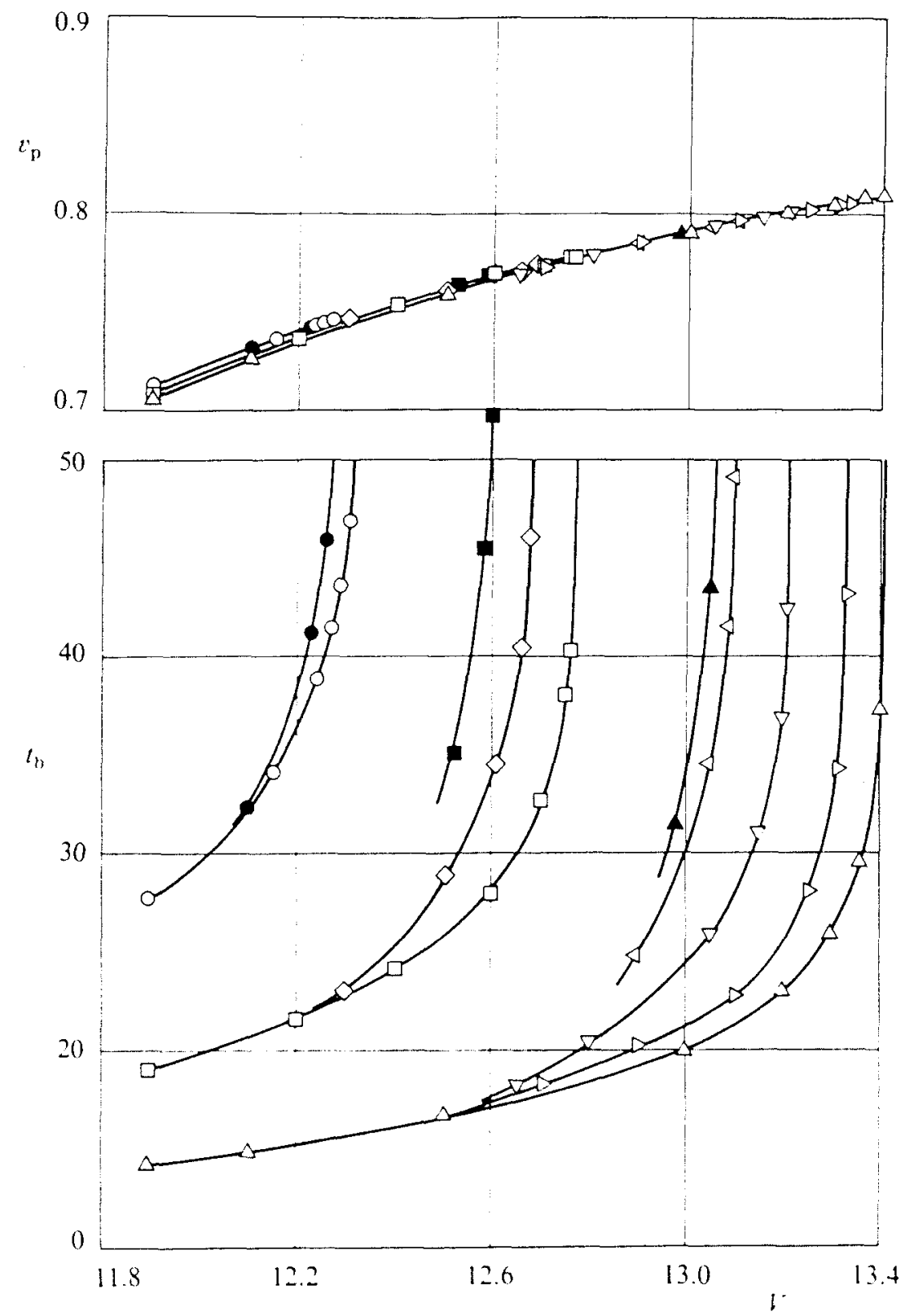

Flacke t. Partial rolume $p_{p}$ and breaking time thersus the volume l' of liquid bridges with a slenderness $1=2.6$. The symbols correspond to the cases numerically solved and indicate the values of initial eonditions and breaking perturbations as in table 1 .

has been plotted instead of $f_{m}$ ). Aceording to this numerical analysis. if $B$ o is small enough. "p depends mainly on easily controlled experimental variables such as the slenderness and the volume of the liquid bridge. This simplifies the method of correlating experimental and numerical results and helps to validate the sliec mond for predieting the dynamic behaviour of liguid bridges.

Static results from this study are compared with these obtained by other investigators. The stability limit of cylindrical liquid bridges subject to axial microgravity has been studied in Meseguer (19836), where the results from ('arruthers \& Grasso (1972). Coriell et al. (1977) and Vega \& Perales (1953) are analyed Some of these results (the variation with $B O$ of the maximum stable slenderness of "rlindrical volume liquid bridges) are presented in table 3. As an be observed. the results obtained in lleseguer (198:3b) give maximum stable slenderness below the values reported here. The difference arises berause the previens results were ralculated assuminer that the liquid eolumn was a eylinder at the initial time. which 

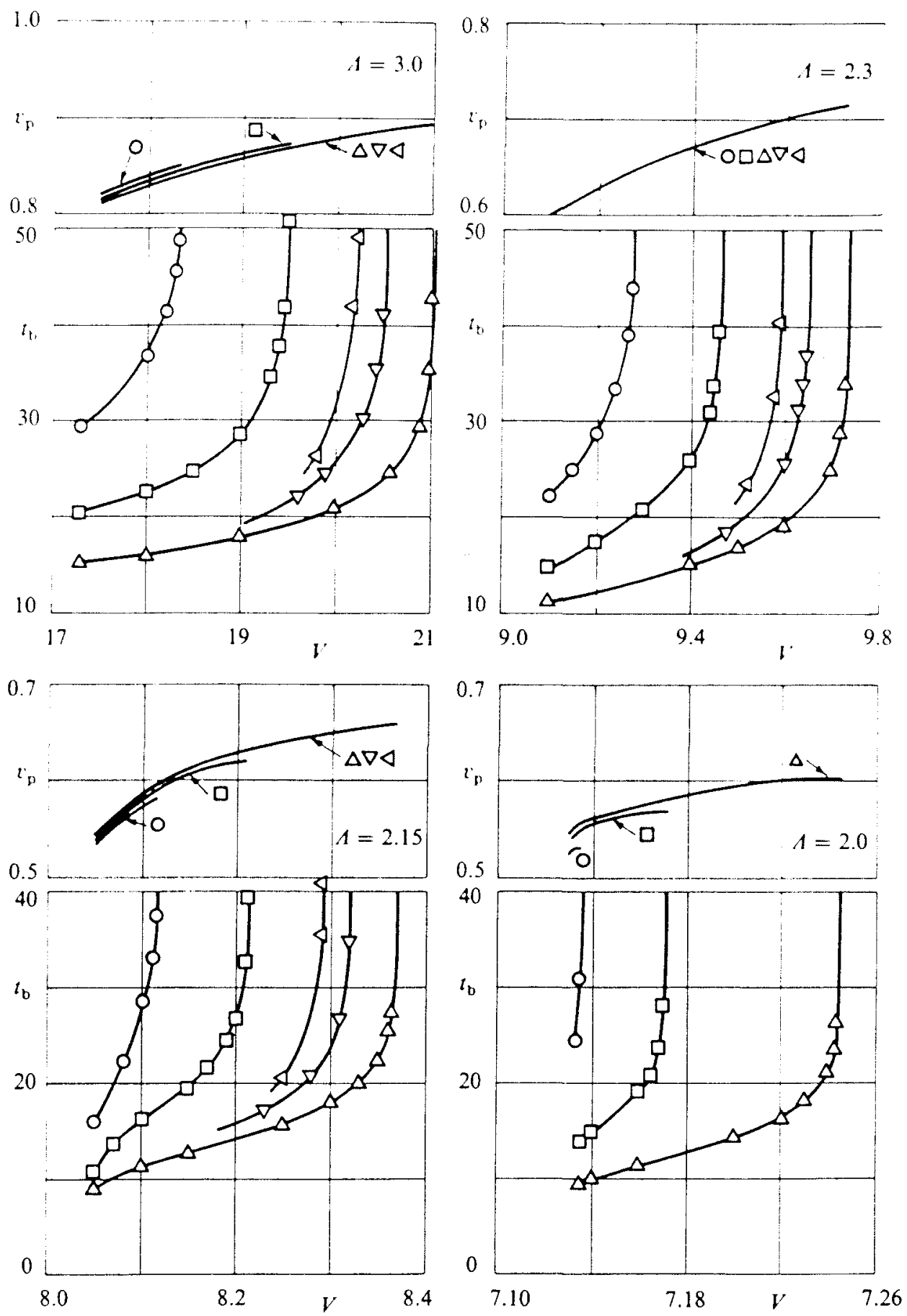

Figcre 5. Partial volume $r_{\mathrm{p}}$ and breaking time $t_{\mathrm{b}}$ versus the volume $l$ of liquid bridges with slenderness $A=3.0,2.3,2.15$ and 2.0 , respectively. The symbols correspond to the cases numerically solved and indicate the values of initial conditions and breaking perturbations as in table 1 .

is the equilibrium shape corresponding to $B i=0$. Since the breaking perturbation increases with $B$, lower values of the maximum stable slenderness should be obtained, as shown here. The numerical results given in this paper agree with those of Coriell et al. (1977). Futhermore, an upper limit $(B o=0.005)$ for the applicability of the results obtained by Vega \& Perales (1983) through a perturbation analysis can also be established. 


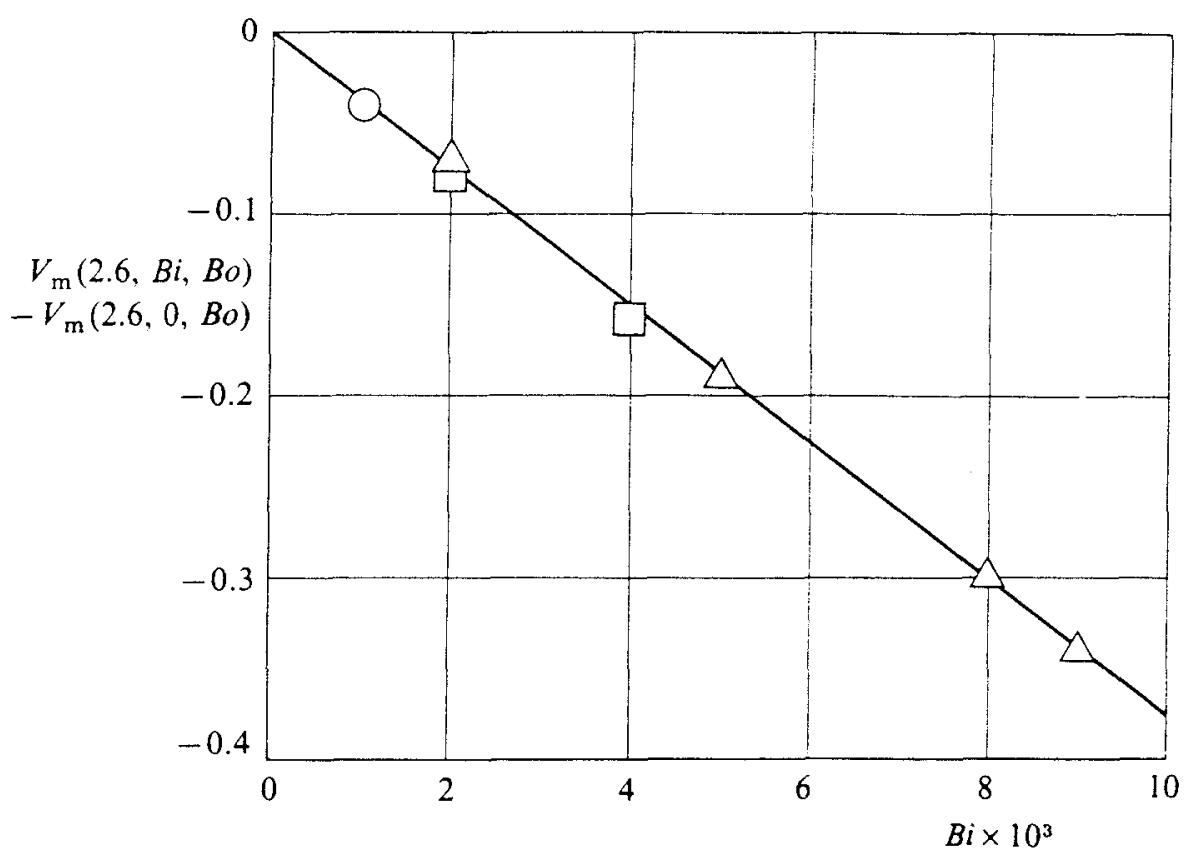

FIGURE 6. Variation of minimum volume stability limit $V_{\mathrm{m}}(2.6, B i, B o)-V_{\mathrm{m}}(2.6 .0, B o)$ with initial conditions $B i$ for liquid bridges with a slenderness $A=2.6$. The symbols indicate the values of Bond number $B o: \triangle, 0.01 ; \square, 0.005: 0,0.002$.

\begin{tabular}{|c|c|c|c|c|c|c|c|c|c|c|c|c|}
\hline \multirow[b]{2}{*}{ Bo } & \multirow[b]{2}{*}{$B i$} & \multirow[b]{2}{*}{ SB } & \multicolumn{2}{|c|}{$A=3.0$} & \multicolumn{2}{|c|}{$A=2.6$} & \multicolumn{2}{|c|}{$A=2.3$} & \multicolumn{2}{|c|}{$\Lambda=2.15$} & \multicolumn{2}{|c|}{$\Lambda=2.0$} \\
\hline & & & $V_{\mathrm{m}}$ & $r_{p}$ & $V_{\mathrm{m}}$ & $v_{p}$ & $r_{\mathrm{m}}$ & $v_{\mathrm{p}}$ & $I_{\mathrm{m}}$ & $i_{p}$ & $V_{\mathrm{m}}$ & $v_{p}$ \\
\hline 0.002 & 0.001 & 0 & - & - & 8 & 0.745 & - & - & - & - & - & - \\
\hline 0.00 & 0 & 0 & 18.40 & 0.850 & 1 & 0.7 & 9.277 & 0.645 & 8.116 & 0.583 & 7.136 & 0.531 \\
\hline 0.005 & 0.0 & $\mathbf{a}$ & - & - & 1 & 0. & - & - & - & - & - & - \\
\hline 0. & 0.0 & $\overline{0}$ & 一 & - & 1 & 0.7 & - & - & - & - & - & - \\
\hline 0.005 & 0 & $\square$ & 19.51 & 0.872 & 12.77 & 0.7 & 9.460 & 0.681 & 8.215 & 0.621 & 7.171 & 0.564 \\
\hline 0.010 & 0.009 & $\Delta$ & - & - & 13.06 & 0.793 & - & - & - & - & - & - \\
\hline 0.010 & 0.008 & $\triangleleft$ & 20.25 & 0.883 & 13.11 & 0.796 & 9.594 & 0.699 & 8.296 & $0.646^{\circ}$ & - & - \\
\hline 0.010 & 0.00 & $\triangle$ & 20.54 & 0.887 & 13.22 & 0.801 & 9.648 & 0.706 & 8.320 & 0.651 & - & - \\
\hline 0.010 & 0.002 & $D$ & - & - & 13.34 & 0.806 & - & - & - & - & 一 & - \\
\hline 0.010 & 0 & $\triangle$ & 21.03 & 0.894 & 13.41 & 0.810 & 9.735 & $0.716^{\circ}$ & 8.367 & 0.659 & 7.245 & 0.602 \\
\hline
\end{tabular}

$B o$. Bond number at breaking: $B i$. Bond number used to calculate the initial-conditions equilibrium interface shapes: SB. symbols indicating the values of both $B o$ and $B i$ in figures 4 and 5: $A$. slenderness: $V_{\mathrm{m}}$, minimum volume stability limit (made dimensionless with $R^{3}$ ) for the corresponding values of $B o$ and $B i: v_{\mathrm{p}}$. partial volume (defined as the ratio of the main drop volume to the whole liquid bridge volume) at the minimum volume stability limit.

TABLE 1

\section{Apparatus}

Experiments have been carried out in a Plateau tank (PT) already described in Martinez \& Rivas (1982) which simulates the Fluid Physics Module (FPM) of the European Space Agency. A dimethyl silicone oil (Rhodorsil 77 V 20) with riscosity 20 times that of water and density $\rho=954 \pm 0.5 \mathrm{~kg} \mathrm{~m}^{-3}$ has been used as working liquid and a mixture of methanol and distilled water as the surrounding liquid. To improve interface visibility the dimethyl silicone oil was dyed slightly with yellow aniline. 


\begin{tabular}{|c|c|c|c|c|c|c|c|c|}
\hline \multirow[b]{2}{*}{$A$} & \multicolumn{2}{|c|}{$B_{0}=0+$} & \multicolumn{2}{|c|}{$B_{0}=0.002$} & \multicolumn{2}{|c|}{$B_{0}=0.005$} & \multicolumn{2}{|c|}{$\left.B_{0}\right)=(1.1 ; 10$} \\
\hline & $\mathrm{I}_{\mathrm{m}}$ & $r_{\mathrm{p}}$ & $r_{\mathrm{m}}$ & $i_{n}$ & $l_{\mathrm{m}}$ & $r_{\mathrm{p}}$ & $r_{\mathrm{m}}$ & $r_{p}$ \\
\hline 3.0 & 17.25 & 0.819 & 18.21 & $0.8+6$ & 19.02 & 0.865 & 20.06 & 0.879 \\
\hline 2.6 & 11.86 & 0.718 & 12.23 & 0.743 & 12.58 & 0.768 & 13.03 & 0.793 \\
\hline 2.3 & 9.099 & 0.586 & 9.242 & 0.636 & 9.372 & 0.665 & 9.560 & 10.697 \\
\hline $2.1 \pi$ & S.1039 & 0.512 & 8.098 & 0.577 & 8.170 & 0.613 & 8.276 & 0.645 \\
\hline 2.0 & 7.127 & $0.5(n)$ & 7.133 & 0.535 & 7.156 & 0.565 & 7.208 & 0.600 \\
\hline
\end{tabular}

Bo. Bond number: $A$. slencierness: $I_{m}$. static minimum volume st ability limit (made dimensionless with $\left.R^{3}\right): r_{p}$. partial volume (defined as the ratio of the main drop volume to the whole liguid bridge volume) at the minimum volume stability limit. I In the case $B_{0}=0$ ) the quoted ralues of $l_{m}$ are from llartinez (1983) and that for $r_{n}$ are from Meseguer et al. (1983).

TABLE :

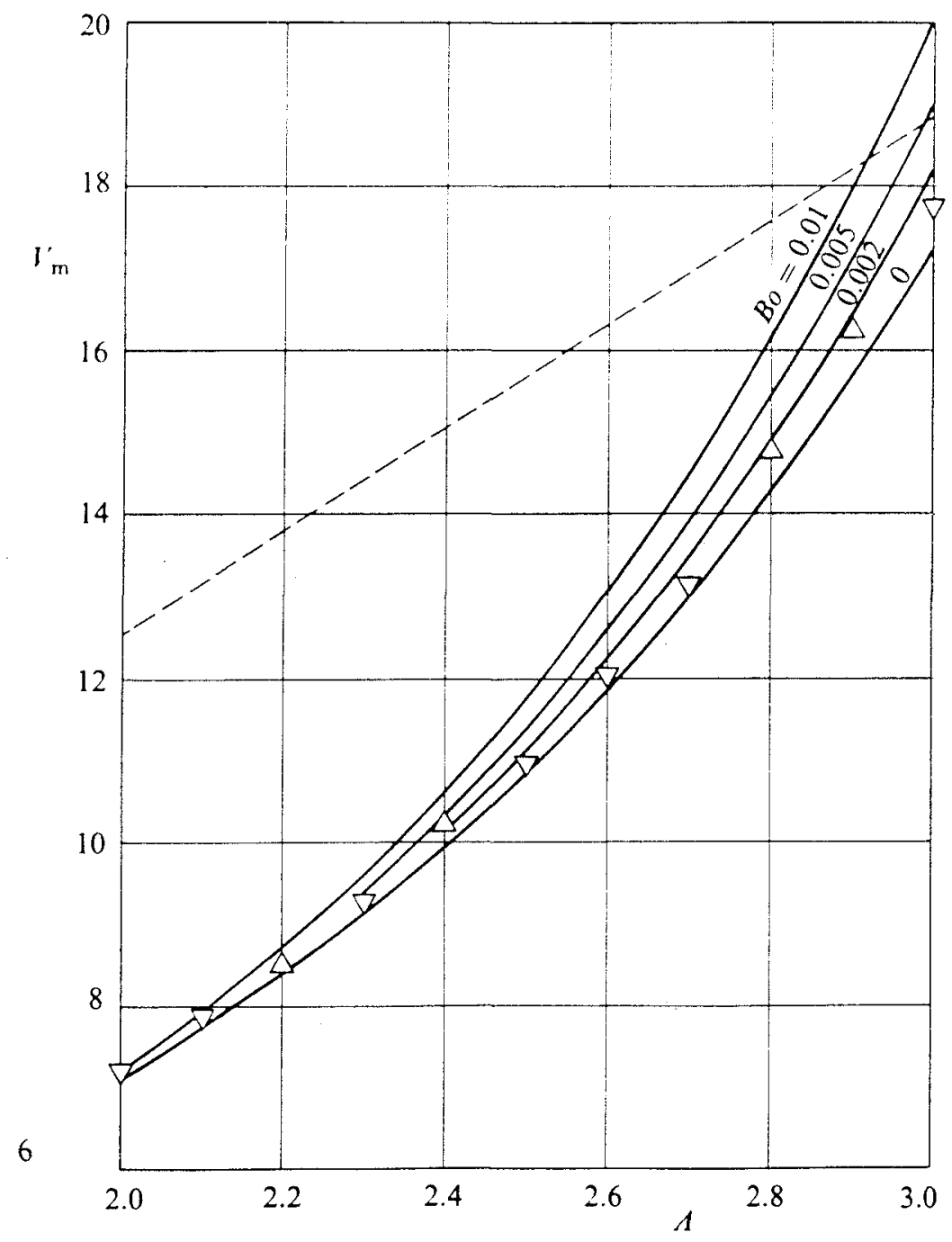

Frgure 7 . Static minimum volume stability limit $V_{\mathrm{m}}$ versus slenderness $A$ for several values of the Bond number Bo. The dashed line corresponds to liquid bridge configurations having cylindrical volume $V=2 \pi A$. The symbols represent experimental results (volume of the liquid bridge at breaking) and indicate the value of the Bond number at breaking: $\nabla,|B o| \leqslant 0.005 ; \triangle$, $|B o|>0.005$. 


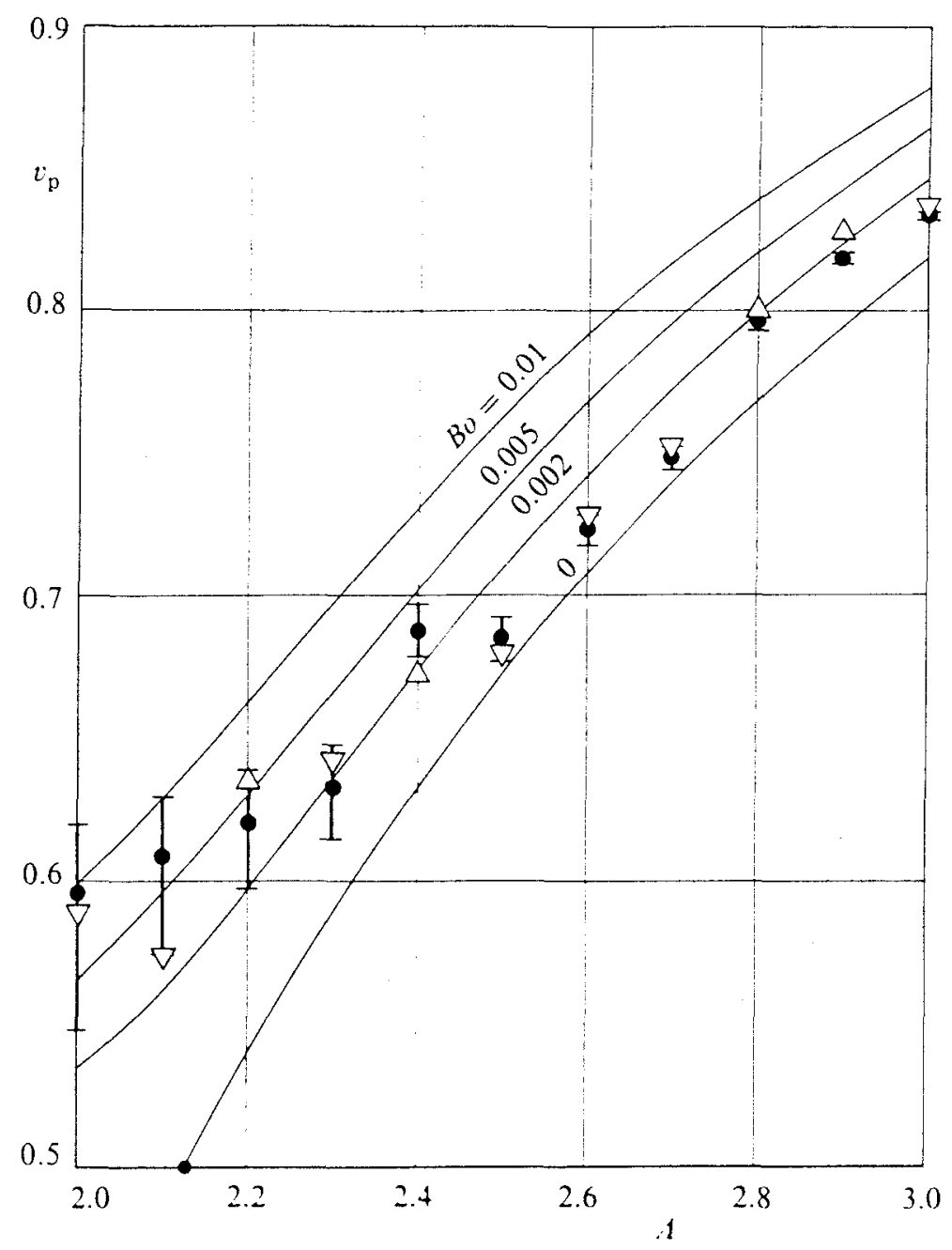

Flacres. Partial volume at the minimum volume stability limit "p versus slenderness $A$ for several values of the Bond number $B o$. The white symbols represent experimental results and indicate the value of the Bond number at breaking: $\nabla .: B 0|\leqslant 0.005: \triangle.| B_{0} \mid>0.005$ : whereas the black symbols indicate the theoretical values of $c_{\mathrm{p}}$ eorresponding to the different experimental liquid bridge contigurations.

The tank. figure 10 . is $140 \times 140 \times 60 \mathrm{~mm}$. with the sides made of $2 \mathrm{~mm}$ thick glass and the bottom of $10 \mathrm{~mm}$ thick Perspex. A remorable plastie sheet minimizes methanol evaporation. The upper disk (the feeding disk). has two movements-rotation and axial displacement. and the bottom disk has three. namely. rotation. axial vibration and lateral displacement. Both disks are made of Perspex. in the shape of a frustrum cone. $15 \mathrm{~mm}$ radius. to provide sharp edges. The injection and remoral of working Huid oecurs through a $4 \mathrm{~mm}$ diameter hole in the eentre of the upper dist. The working surface of the bottom disk is Hat. whereas the working surface of the feeding disk presents a slight conicity to facilitate the evacuation through the injection hole of a ir bubbles trapped in the liquid bridge. Working-fluid injection and removal is made with a calibrated sy ringe. with the piston driven by a variable-speed electric motor. Liquid displared by the piston passes through the filling duct. to which a three-way value with a purere duet is connected. The purge duet is placed so ats to trap a ir bubbles coming from the upper disk. The crror in volume introduced by these air bubbles an be compensated for by measuring the change in height in the purge dure. The system was calibrated by using a burette with a precision of $\pm 0.2\left(\mathrm{~m}^{3}\right.$. which can be taken as the precision of volume measurements. 




Figro 9. Partial volume $r_{\mathrm{p}}$ versus the static minimum volume stability limit $V_{m}$. The symbols correspond to the values obtained from the numerical analysis performed. Numbers on the curves indicate the values of the slenderness $A$ (continuous lines) and the Bond number $B O$ (dashed lines).

\begin{tabular}{cccccc} 
& \multicolumn{5}{c}{$A_{\text {cr }}$} \\
\cline { 2 - 6 }$B o$ & $a$ & $b$ & $c$ & $d$ & $e$ \\
0.002 & 3.14 & 3.06 & 3.06 & 3.05 & 3.05 \\
0.005 & 3.13 & 2.98 & 3.00 & 2.97 & 2.99 \\
0.010 & 3.13 & 2.89 & 2.92 & 2.88 & 2.92
\end{tabular}

$B o$. Bond number: $A_{\mathrm{cr}}$. maximum stable slenderness of cylindrical volume liquid bridges for the corresponding Bond number. The values quoted are from $(a)$ Carruthers \& Grasso (1972): $(b)$ Vega \& Perales (1983): (c) Coriell et al. (1977): (d) Meseguer (1983b) and (e) calculated in this paper.

TABLE 3

The PT was not thermostated, but the temperature of the surrounding liquid was continuously measured using a thermometer with a precision of $\pm 0.1^{\circ} \mathrm{C}$. A magnetic stirrer at one side of the tank helped to keep uniform the temperature and alcohol composition. Background illumination consisted of a $60 \mathrm{~W}$ blue glass lamp with a $10 \mathrm{~mm}$ water filter $20 \mathrm{~cm}$ behind the rear glass of the tank. Very close to the rear face of the tank a translucent grid provided diffuse illumination and a reference frame for interface shape measurements (see figure 11). A photo-camera and a video-camera, $70 \mathrm{~cm}$ away, were used for image recording. A digital clock display was placed on the video-camera-viewed background for registration of the elapsed time. 


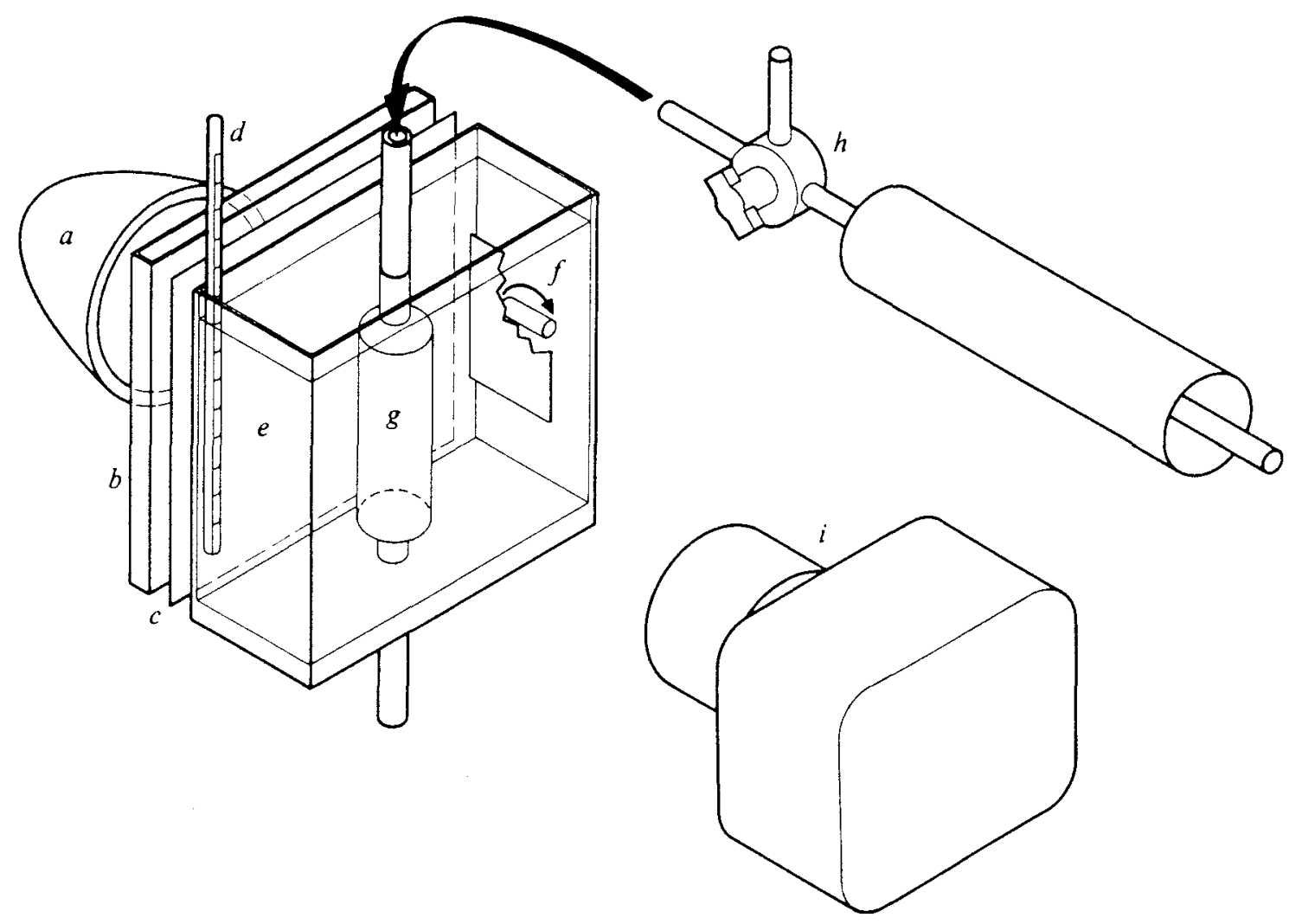

Figure 10. Experimental arrangement: $(a)$ light source, $(b)$ water filter, $(c)$ translucent grid. $(d)$ thermometer, $(e)$ tank. $(f)$ magnetic stirrer, $(g)$ liquid bridge. $(h)$ filling and purge system $(i)$ image recording sustems.

\subsection{Time variation of Bond number}

In PT experiments the Bond number is defined as $B o=\Delta \rho g R^{2} / \sigma$. where $\Delta \rho$ is the difference between the liquid densities, $g$ is the acceleration due to gravity, $R$ the radius of the disks and $\sigma$ the interfacial surface tension. Under these conditions density matching must be very accurate to obtain very small $B$ o values.

Methanol evaporation could not be completely aroided, and therefore an experiment was designed to measure the time variation of $B o$. The same liquid bridge was used as a density indicator. In effect. to a first approximation. the equilibrium interface shape of a cylindrical liquid bridge subject to the action of an axial microgravity is (.Meseguer 1983b)

$$
F(z)=1+B o\left(z-\frac{A}{\sin A} \sin z\right) .
$$

the maximum and the minimum liquid bridge radii. $F_{\max }$ and $F_{\min }$, being reached at $z_{m}= \pm \cos ^{-1}([\sin A] / A)$. In consequence. the Bond number is related to the liquid bridge deformation through

$$
B_{0}=\frac{1}{2} \frac{F_{\max }-F_{\min }}{z_{\mathrm{m}}-\frac{A}{\sin A} \sin z_{\mathrm{m}}} .
$$

It is assumed that $B o$ is positive $(B o>0)$ when the liquid bridge is inside another liquid with an excess of methanol (the liquid bridge density is greater than the surrounding liquid density and the interface shape distorts. bulging out near the bottom disk and necking in at the upper), and negative $\left(B_{0}<0\right)$ when. due to methanol evaporation. the surrounding liquid density becomes greater than that of the liquid bridge (the interface shape is in opposition to that described above). 



Flgrke 11. Photographs of liquid bridges, with slendernesses 2.0 and 3.0 respectively, before and after breaking. showing the magnifying-glass effect of the liquid column. 


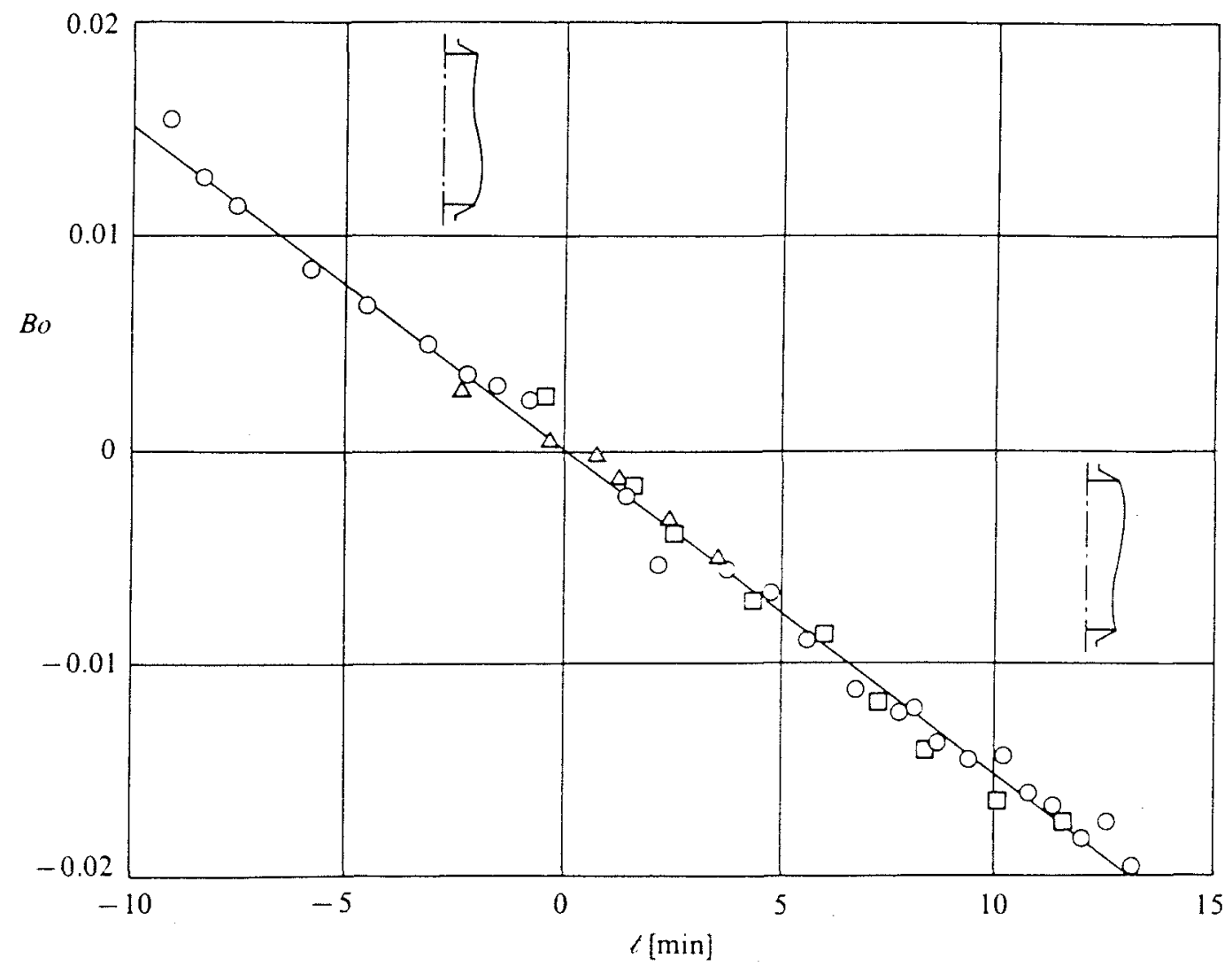

Figere 12. Variation of Bond number Bo with dimensional time $t$. The symbols indicate the slenderness of the liquid bridge and the interval of temperatures during experiments: 0.2 .77 . $23.7-24.1^{\circ}{ }^{\circ} ; \square, 2.77,27.0-27.3^{\circ}\left(\div ; \triangle, 3.0 .26 .6-26.7^{\circ}\left({ }^{\prime}\right.\right.$.

Three calibration tests using cylindrical volume liquid bridges were performed. two of them at $A=2.77$ and the third at $A=3.0$. From time to time photographs of the liquid bridge interface were taken. $F_{\max }$ and $F_{\min }$ were measured from these pictures and $B_{0}$ (alculated from (5.2). The results obtained are plotted in figure 12 . There is an almost linear dependence of Bond number with time. the rate of change being $\mathrm{d} B \mathrm{~B} / \mathrm{d} t=-1.53 \times 10^{-3} \mathrm{~min}^{-1}, t$ being the dimensional time. A detailed study of this phenomenon can be found in Sanz (198:3).

\section{Experimental technique and results}

At the beginning of all the experiments the surrounding liquid had methanol in excess. its density being slightly smaller than the liquid hridge density aiming to provide a positive $B o$ (see figure 12 ) so that $B$ o was close to zero at the breaking time.

After density matching using a longer cylindrical eolumn the desired slenderness and rolume were fixed. The slenderness was reduced to the prefixed ralue, and some liquid was sucked from the bridge to maintain the "ylindrical volume. Once $A$ had been obtained. the liquid suction continued in two stages. Slow but entinuous withdrawal of Huid brought the liquid bridge to the vieinity of the theoretical limit of minimum rolume for $B o=0.01$ cobviously. this first stage is suppressed in the breaking at $A=3.0$. see figure 7 ). Then very show withdrawal oceured in steps of

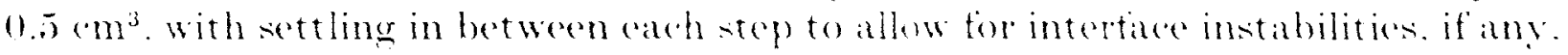
to derelop. Suction in this last stage must be performed at very low speeds to arobl

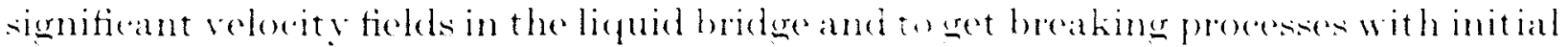
conditions as close as possible to these stated in $\$ 2$. the suetion rate being smaller as .1 terereatses. 


\begin{tabular}{|c|c|c|c|c|c|c|c|}
\hline$A_{\mathrm{i}}$ & $A_{\mathrm{b}}$ & $B c_{\mathrm{i}} \times 10^{3}$ & $B\left(s_{b}\right) \times 10^{3}$ & $t_{n}-t_{i}|\min |$ & $I^{\circ} \pm 0.066$ & $r_{\mathrm{p}}$ & 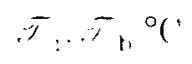 \\
\hline 2.77 & 2.0 & 14 & -2 & 10.5 & 7.20 & 0.589 & 23.5 .23 .6 \\
\hline 2.77 & 2.1 & 14 & -4 & 12.11 & 7.8 .5 & 0.573 & 23.9 .24 .3 \\
\hline 2.77 & 2.2 & 10 & -10 & 13.0 & 8.52 & 0.6335 & 27.2 .27 .4 \\
\hline 2.77 & 2.3 & 10 & 2 & 5.0 & 9.23 & 0.642 & 2.5 .6 .257 \\
\hline 2.77 & 2.4 & 13 & -10 & 15.3 & 10.23 & 0.672 & $2: 3.5 .2+40$ \\
\hline 2.77 & 2.5 & 10 & 1 & 5,6 & 10.93 & 0.680 & 23.7 .8 .8 \\
\hline 2.77 & 2.6 & 22 & -5 & 17.6 & $1: .01$ & 0.728 & 26.3 .26 .8 \\
\hline 3.0 & 2.7 & 6 & -4 & 6.8 & 13.11 & 0.752 & 25.7 .25 .8 \\
\hline 3.0 & 2.8 & 1 & -8 & 5. .9 & 14.81 & 0.8011 & 27.1 .27 .2 \\
\hline 3.0 & 2.9 & -1 & -6 & 3.0 & 16.29 & 0.528 & $2-.3 .27 .5$ \\
\hline 3.1 & 3.0 & 2 & -2 & 2.7 & 17.73 & 0.537 & 20.1 .26 .2 \\
\hline
\end{tabular}

A. senderness: Bo. Bond number: t. dimensional time: $V$. volume of the liquid bridge at breaking (made dimensionless with $P^{3}: c_{\mathrm{p}}$. partial rolume. defined as the ratio of the main drop volume to the whole liquid bridge volume: $\mathscr{T}$. dimensional temperature. The subscripts $\mathrm{i}$ and $\mathrm{b}$ refer to starting time (density matching) and to breaking time respectively.

TABLE 4

In each run photographs were taken after the density matching. after every rolume change step, and after the breakage takes place, the video-camera being used for recording the stepped withdrawal and the subsequent breaking process. The volume of the drops was calculated by numerical integration of the drop interface shapes from the pietures. To determine the interface shapes the grid placed at the rear face of the P'T provided an accurate reference frame: pict ures were enlarged and the diameter of the drops at each horizontal grid line as well as the distance bet ween two reference vertical grid lines were measured. Then, taking into account both scale and conicity effects, the real diameters were calculated and from these last values the volume of the drops was obtained.

The experimental results are shown in table 4. For every experiment, the initial Bond number $B o_{i}$ refers to that determined from the density-matching picture (the zero time being reset at the instant that photograph was taken). and is calculated as explained in $\$ 5.1$. The Bond number at breaking $B o_{b}$ is calculated from $B o_{i}$ and the measured time elapsed until the liquid bridge reaches its minimum rolume stability limit, just before the breaking process accelerates, assuming the rariation of Bond number with time to behare as in figure 12 .

The control of Bond number seems to be the weak link in this set of experiments. In several experiments a bias has been introduced because of an optimistic estimation of the smallness of Bond number (and maybe because of a wrong estimation of the liquid bridge evolution rate, probably caused by the slowness of the beginning of the breaking process). Therefore, in some cases the liquid bridge volume has been excessively reduced. When, afterwards, $B o$ is calculated it is found that the liquid bridge has been forced to break with a volume less than that for the corresponding static minimum volume stability limit, as shown in figure 7 , where experimental results giving the liquid bridge volume at breaking as a function of $A$ are shown.

In figure 8 the experimental partial volumes $v_{\mathrm{p}}$ are plotted against $A$. Experimental and numerical results agree in the sense that $v_{p}$ increases with $A$, although the influence on Bond number is not clearly indicated by experimental results for the reasons already stated: most of the experimental results correspond to liquid bridge configurations below the stability limit. In spite of this, since $v_{p}$ is almost independent 
of $B o$ (see figures 4 and 5 ), it is possible to calculate from figure 9 the partial volumes corresponding to experimental configurations. These numerical results are also plotted in figure 8. Although experimental values of the liquid bridge volume are given with an error of \pm 0.06 (in dimensionless variables) which is constant for the whole range, the error in numerical partial volume increases as $A$ decreases. as shown in figure 9. Numerical and experimental results are in agreement, except on a couple of points. The concordance is encouraging because. according to these experiments, the one-dimensional inviscid slice model accurately predicts the behaviour of axisymmetric liquid bridges, at least with respect to the aspects of the breaking problem treated in this paper.

\section{Conclusions}

The influence of the Bond number on the static minimum volume stability limit has been studied from a dynamic point of view by using a one-dimensional inviscid slice model. Additionally, this slice model has been used to calculate stable liquid bridge equilibrium shapes, providing a method of calculation in which the input variables are ones the experimentalist may easily control. These are the slenderness and the liquid bridge volume.

The influence of the slenderness, the volume, and the Bond number on the volume of the drops resulting after the liquid bridge breaking has been analysed. Numerical results show that partial volume depends mainly on the slenderness and on the whole of the liquid bridge, but not on the breaking perturbation. On the other hand. experimental results indicate that the one-dimensional slice model is very suitable for predicting the behaviour of axisymmetric slender liquid bridges, in spite of the simplifying hypotheses introduced in the theoretical model (the axial velocity is assumed to be constant over each slice and the radial momentum equation is not considered).

To conclude, it should be remembered that calculations are stopped before the neck radius vanished; in the subsequent evolution the liquid bridge splits in two drops (leaving apart satellite droplets) which remain anchored to the disks. This last part of the evolution has not been studied here, although some attempts in connection with this subject can be found in the literature. For instance, the work of Keller \& Miksis (1983) could be a guide for study of the smoothing of the sharp apices appearing on the drops just after breakage. An estimation of the influence of microgravity on the final shape of these drops (which are spherical caps in the case $B o=0$ ) can be found in Chesters (1977).

This work has been supported by the Spanish National Commission for Space Research (CONIE) under a contract with the Polytechnic University of Madrid (CPM).

\section{REFEREN('ES'}

Bisch. C.. LASEK. A. \& Rodot. H. 198: Hydrodynamic behaviour of spherical semi-free liquid volumes in simulated weightlessness. J. Héc. Theorique ot Appliquee 1, 165-183.

Borcher. E. A.\& Evass. M. J. B. 1980 Properties of fluid bridges between solids in a gravitational field. J. Colloid Interface sci. 75. 409-418.

Browx. R. A. \& Sorrvex. L. E. 1980 The shapes and stability of captive rotating drops. Phil. Trans. R. Sioc. Lond. A 297, 51-79.

Carrethers. J. R. \& (iRasso, .11. 1972 The stabilities of floating liquid zones in simulated zero gravity. $J$. C'ryst. Growth 13/14, 611-614. 


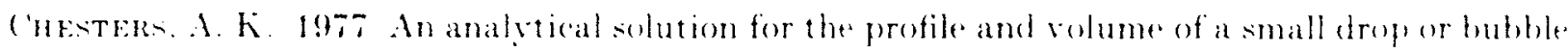

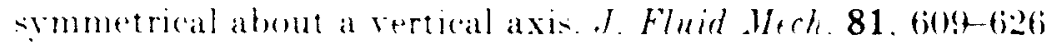

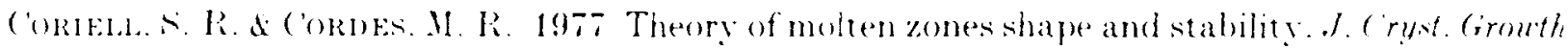
42. $46(i-472$.

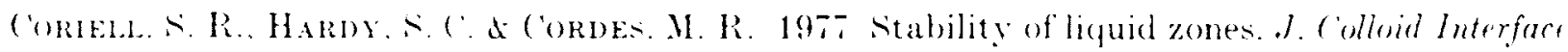
다. $60.12(-136$.

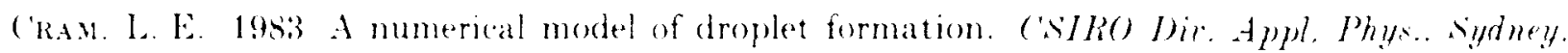
Australia 2070 .

DA RMA. I. 1981 Stability of liguid bridges. In Applications of Space Technology (ed. L. (i.



I) RWA. I. A Maxzaxo. 1). R. 1981 Impulsive motions of the float ing zone. P('H Physicochemical Hydrolymamion 2. 16ir-176.

I) Riva. I \& Martinez. I. 1979 Floating zone stability (Exp. 1-Es-331). In Material siciences in space ExA Sil'-142. PH. 67-73. Paris: Est.

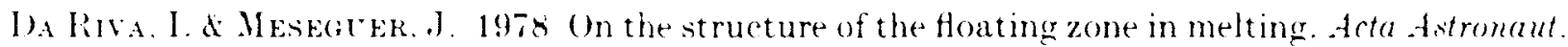
5. $637-653.3$.

Elatix. M. P. LeBener. A. P. \& Tsmeler. A. V. 1982 Laboratory modeling of the stability and dynamies of free liquid zones. In Hydromechanics and Heat and Hass Tranefer in Zere-Cravity (in Russian) (ed. V. S. Avduevskii d V. I. Polezhaev). pp. 24-33. Moseow : Nauka.

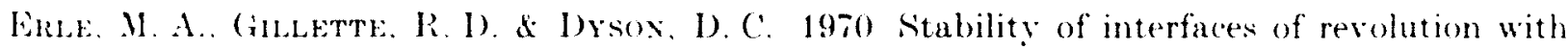
constant surface tension. The case of eatenoid. Chem. Engmg J. 1, 97-109.

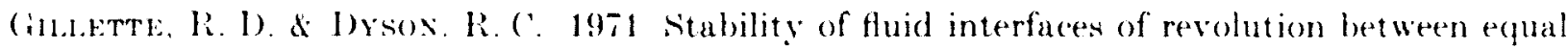
solid circular plates. (hem. Engng .J. 2, 44-54.

HARRoT, (i. M. \& BRowx. R. A. 1983 Flow in a differentially rotated cylindrical drop at low liegnolds number. I. Fluid . Wech. 126. $269+285$.

Hayves. J. .I. 1970 Stubility of a fluid eylinder. J. Colloid Interface Sici. 32, 652-6int.

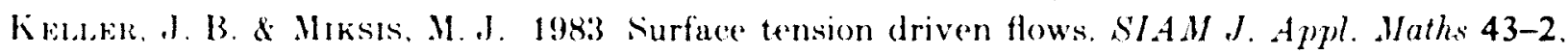
$268-277$.

LAE. H. ('. 1974 I)rop formation in a liquid jet. IB.V .J. Res. Dev. 18. 364-369.

Maktinkz. I. 1976 Floating zone under reduced gravity. Axisymmetric equilibrium shapes. In Material Sriences in Space ESA SP-114, pp. 277-282. Paris: ESA.

Mantixez. I. 1978a Hidrostática de la zona flotante. Tesis doctoral, Universidad Politécnica de Madrid.

Martinez. I. 19786 Floating zones. Equilibrium shapes and stability criteria. In COSPAR: Space Research Vol. xvil (ed. M. J. Rycroft \& A. C. Strickland), pp. 519-522. Pergamon.

Martinez. I. 1983 Stability of axisymmetric liquid bridges. In Material Sciences under Hicrogravity ESA SP-191. pp. 267-273. Paris: ESA.

Martinez. 1. \& Rivas, D. 1982 Plateau Tank Facility for simulation of Spacelab experiments. Acta Astronaut. 9, 339-342.

Masox, G.C. 1970 An experimental determination of the stable length of cylindrical liquid bubbles. J. Colloid Interface Sci. 32.172-176.

Mesegcer, J. $1983 a$ The breaking of axisymmetric liquid bridges. J. Fluid Hech. 130, $123-151$.

Meseguer, J. $1983 b$ The influence of axial microgravity on the breakage of axisymmetric liquid bridges. J. Cryst. Grouth 62,577-586.

Mesegter, J. 1984 Stability of slender, axisymmetric liquid bridges between unequal disks. $J$. Cryst. Growth 67, 141-143.

Meseguer, J., Saxz, A. \& Rrvas, D. 1983 The breaking of axisymmetric non-cylindrical liquid bridges. In Materials Sciences under Microgravity ESA SP-191, pp. 261-265. Paris: ESA.

Pimbley, W. T. 1976 Drop formation from a liquid jet: a linear one-dimensional analysis considered as a boundary value problem. IBM J. Res. Dev. 20, 148-156.

Pimbley, W. T. \& Lee, H. C. 1977 Satellite droplet formation in a liquid jet. IBM J. Res. Der. 21. $21-30$.

Rivas, D. \& Meseguer. J. 1984 One-dimensional, self-similar solution of the dynamics of axisymmetric slender liquid bridges. J. Fluid Mech. 138, 417-429. 
Rodot, H.. Bisch, C. \& LASEK, A. 1979 Zero gravity simulation of liquids in contact with a solid surface. Acta Astronaut. 6. 1083-1092.

SAxz. A. 1983 Comportamiento de las zonas liquidas flotantes en microgravedad simulada. Tesis doctoral. Universidad Politécnica de Madrid.

Sanz, A. \& Martinez. I. 1983 Minimum volume for a liquid bridge between equal disks. J. Colloid Interface Sci. 93, 235-240.

Slobozhasis, L. A. 1982 Problems on the stability of liquids in equilibrium. appearing in spatial technology. In Hydromechanics and Heat and Mass Transfer in Zero-(ravity (in Russian) (ed. Y. S. Avduerskii \& V. I. Polezhaev). pp. 9-24. Moscow: Nauka.

Tagg. R.. Cammack. L., Cronquist, A. \& Wang, T. G. 1980 Rotating liquid drops: Plateau's experiment revisited. JPL 900-954, Jet Propulsion Laboratory Caltech. Pasadena. California.

Lvar. L. H. \& Brow. R. A. 1982 The dependence of the shape and stability of eaptive rotating drops on multiple parameters. Phil. Trans. R. Soc. Lond. A 306. 347-370.

Veg. J. M. \& Perales. J. M. 1983 Almost cylindrical isorotating liquid bridges for small Bond numbers. In Materials Sciences under Microgravity ESA SP-191. pp. 247-252. Paris: ESA. 